\title{
História fotografada, história (com)partilhada: imagens e vozes de Cotia
}

Resumo

Esse artigo discorrerá sobre os caminhos - teóricos ou não condutores à construção do blog - álbum - do cotidiano de moradores da cidade de Cotia: História Fotografada, História (Com)Partilhada. O blog surge do desejo de experimentação de novas metodologias para o ensino da linguagem popular e culta, da narração pela palavra e pela imagem, e centra-se em fragmentos narrados da história de fotografias escolhidas pelos personagens centrais do momento capturado por elas. Esses fragmentos fazem parte de textos transcritos e transcriados pelos alunos de Comunicação e Expressão dos Cursos de Gestão Empresarial e Gestão da Produção Industrial da Fatec Cotia.

Palavras-chave: Linguagem oral, linguagem escrita, histórias de vida 


\title{
História fotografada, história (com)partilhada: imágenes y voces de cotia
}

\author{
SANDRA REGINA CHAVES NUNES
}

\section{Resumen}

Ese texto discurrirá acerca de los caminos - teóricos o no - conductores hacia la construcción de un blog - álbum del cotidiano de moradores de la ciudad de Cotia: História Fotografada, História (Com)Partilhada. El blog surge del deseo de la experimentación de nuevas metodologías para la enseñanza del lenguaje popular y culto, de la narración por la palabra y por la imagem y se centra en fragmentos narrados de la história de fotografías electas por los personajes centrales del momento capturado por ellas. Esos fragmentos son partes de los textos transcriptos y "transcriados" por los alumnos de Comunicación y Expresión de os Cursos de Gestión Empresarial y Gestión de la Producción Industrial de Palabras clave: Fatec Cotia. 


\title{
Photographed history, shared history: images and voices of Cotia
}

\section{SANDRA REGINA CHAVES NUNES}

\begin{abstract}
This text will be based on the - theoretical or nontheoretical - conducting paths towards the construction of a blog - album - on the daily life of Cotia's residents: História Fotografada, História (Com)Partilhada. The blog emerges from the desire to experiment with new methodologies for the teaching of popular language and culture, narration by word and image, and it focuses on narrated fragments from the history of photographs chosen by the central characters of the moment captured by the photographs. These fragments are part of the texts transcripted and "transcribed" by the students of Communication and Expression of Business Management Courses and Management of Industrial Production of Fatec Cotia.
\end{abstract}

Keywords:

Oral language, written language, life histories 
Algumas vivências e pessoas são fundamentais para aguçar o desejo de expansão de limites. Não cabe aqui elencar os responsáveis por incentivar-me a extrapolar as fronteiras entre os saberes, mas cabe citar os que se imbricam nas reflexões que farão parte deste artigo: Zilda Iokoi, José Carlos Sebe, Eneida Maria de Souza, José Ribeiro e Claudia Moraes. Com eles, passei a ouvir mais atentamente as pessoas, seus relatos, suas imagens... Com eles, rememorei que os livros que mais me marcaram narravam a vida de homens comuns. Revi imagens e paisagens.

Com os historiadores, pela História Oral, exercitei a escuta de histórias de vida. Com o antropólogo-cineasta, reconheci a experiência projetada em imagens e a riqueza das menores coisas. Com a crítica literária, enveredei pela biografia de autores e daqueles que fazem parte da história cultural de uma determinada época. Três áreas cruzaram-se: História, Artes Visuais e Literatura.

Se pessoas inspiram, encontros materializam ações. Em Ovar, cidade próxima a Avancal, Portugal, uma proposta feita por José Ribeiro a duas aprendizes - Claudia Moraes e eu ávidas por deslocarem-se da palavra para a imagem instaurou o olhar fotográfico: busquemos - registremos - aonde nos leva o azul! Um azul que se encontrava em uma praça, mas percorria a Cidade dos Azulejos. Das câmeras na mão, nasceu um pequeno ensaio. Nesse percurso, meus olhos reavivaram as leituras de Cortázar e das linhas guias do enredo de uma de suas tramas.

Ainda em Portugal, agora em Melgaço, outro Festival de Cinema, o Filmes do Homemz, enveredou-me por histórias absolutamente singulares, seja pelas exposições fotográficas, seja pelos filmes, seja pelas experiências apresentadas no Fora 
de Campo, curso ministrado como parte do Festival. E outro autor vinha-me constantemente à lembrança: Baudelaire! Baudelaire e sua visão do artista e da modernidade!

O poeta francês, em o Pintor da Vida Moderna (BAUDELAIRE, 2010), define o artista como homem da multidão e homem do mundo. A associação refere-se ao pressuposto de que caberia ao artista registrar e imortalizar uma determinada época e a sua história cultural. A homem do mundo e homem da multidão relacionavam-se o homem comum e os heroísmos cotidianos que não se encontram nas construções estéticas aniquiladoras das singularidades.

As palavras do autor habitam-me desde a leitura desse livro, mas floresceram de maneira contundente regadas pela Etnografia Audiovisual e, sobretudo, pela História Oral, pois a concepção baudelariana para o papel do artista e a sua função de registro da "modernidade" permite que se pense em história cotidiana, em história do tempo presente. História dos que pertencem à história e acabam por ser alijados dela.

Antiga faz-se a parceria entre oralidade, literatura e história. A narrativa sobre o passado e sobre as experiências culturais permitiu manter viva a história e a memória de uma determinada sociedade. A oralidade, na contemporaneidade, ainda permanece relevante para a construção do tempo presente.

Paul Thompson (1992) define a História Oral como uma interpretação da história, das sociedades, das experiências sociais e da cultura, cuja centralidade reside na fala. Ao centrar-se na expressão oral do indivíduo e de seu grupo social, a escuta converte-se em método histórico, por se tratar de uma escuta que aciona a voz daquele que se expressa. A construção de narrativas históricas pela oralidade provoca um deslocamento do produtor da narrativa, pois o que ouve, e consequentemente escreve, torna-se um interlocutor, um produtor de conhecimento que primeiro escutou passivamente para assumir depois seu lugar de narrador, assim como aquele que fala inicialmente participa da experiência como um narrador, como alguém elaborador de sua própria fala e organizador de seus pensamentos. (THOMPSON, 1992; MORAES, NUNES, 2016).

A História Oral utiliza-se da história falada, fugindo da experiência clássica, propiciando uma experiência em que sujeitos de um processo, de um lugar social, de um território, de um campo cultural narram o seu tempo/espaço, o seu passado, o seu presente, um acontecimento ou a própria vida. 
Da (con)vivência com esses pesquisadores, com as Artes Visuais, a Literatura e a História Oral brotou um álbum-blog do cotidiano de moradores da cidade de Cotia: História Fotografada, História (Com)Partilhada. ${ }^{3}$

História Fotografada, História (Com)Partilhada surge, então, como fruto dessa fertilização e pretende reviver e reavivar a memória local, com as histórias de pessoas comuns, em sua grandiosidade cotidiana. O blog centra-se em fragmentos narrados da história de fotografias escolhidas pelos personagens centrais do momento capturado por elas. Esses fragmentos fazem parte de textos transcritos e transcriados pelos alunos de Comunicação e Expressão dos Cursos de Gestão Empresarial e Gestão da Produção Industrial da Fatec Cotia.

Cotia é um município localizado na região metropolitana da cidade de São Paulo, com 201.15o habitantes, segundo o último censo do IBGE, de 2015. Uma região marcada por um crescimento desigual e excludente. Em 2014, cria-se a Fatec Cotia, instituição pública de ensino superior administrada pelo Centro Paula Souza, autarquia vinculada à Secretaria de Desenvolvimento Econômico, Ciência, Tecnologia e Inovação do Estado de São Paulo. Nessa Faculdade, oferecem-se dois cursos: Gestão Empresarial e Gestão da Produção Industrial.

E por que criar um blog com histórias cotidianas, que revive e reaviva a memória local, pela fotografia, em uma disciplina de Comunicação e Expressão de Cursos de Gestão? Desde a Poética de Aristóteles, discutem-se as convergências e divergências da construção discursiva e narrativa na História e Literatura. As especificidades dos diferentes discursos constituíram-se, ainda, objeto dos estudos e ensino linguísticos. Nesse campo, deve-se compreender o termo discurso como a atividade comunicativa que engloba tanto o enunciado originário como as condições nas quais ele se produziu, relacionando-se com outros produzidos e constituindo diálogos.4 Sua manifestação dá-se por meio de textos, vistos como produtos significativos e acabados, com qualquer extensão, de uma atividade discursiva escrita ou oral. Os textos organizam-se por gêneros constituintes de formas relativamente estáveis de enunciados, determinados historicamente. Outras linhas teóricas da Teoria da Comunicação e Semiótica ampliaram o conceito de texto para outras construções discursivas e linguagens que não só a verbal.

Coadunando com essas áreas do conhecimento, a língua portuguesa deveria ser apresentada pela relação intrínseca entre sociedade e comunicação, observando que a língua se 
faz uma das suas possibilidades de expressão, cujo ensino não estaria a serviço do oprimir, mas sim do libertar, já que todos podem acessar e se deslocar pelas formas linguísticas. Estabelecer uma relação entre língua e linguagem - ou linguagens - permitiria ampliar o sentido de texto nas disciplinas de Comunicação e Expressão, para propiciar ao aluno o direito de expressar-se como lhe parecesse melhor no contexto de um processo comunicacional, e conhecer que a norma culta poderia lhe ser útil em algumas esferas da vida.

A escrita necessita de consciência de linguagem. O gênio é o esforço, dizia Flaubert (1993) em suas Cartas Exemplares, ao questionar a ideia romântica de que a escrita seria um dom e fruto da inspiração de uns poucos dotados. Se a ilusão de gênio criador era absolutamente necessária numa sociedade em que o artista rompia com regras aprisionadoras, tornava-se igualmente necessário, posteriormente, aclarar que a nomeação era metafórica, pois se referia à singularidade dos procedimentos artísticos e dos conhecimentos linguísticos para recriar a realidade. "As palavras me são arrancadas à força de alicates", lamentava cem anos mais tarde, do outro lado do Atlântico, no Brasil, o escritor mineiro Murilo Rubião (apud MORAES, 1995, p. 23). Relembrar esses dois autores e suas angústias perante a escrita permitiria aos alunos se identificar com um sentimento recorrente quando nos vemos tendo que romper o branco de uma folha de papel. Escrever não é para uns poucos - ainda que saibamos que muitos fatores influem no letramento -, mas é para os que desejam adentrar nesse universo pedinte do debruçar-se sobre o jogo da seleção e combinação. Desmistificar o gênio criador ajudaria a quebrar um pouco o receio de aproximar-se da língua portuguesa e da norma culta. $\mathrm{O}$ aluno poderia escrever se quisesse, contudo tinha de saber que isso exigia esforço, logo não era só uma questão de capacidade ou incapacidade, mas também de dedicação.

Isto aclarado, percebi que a relação com a leitura e a escrita se tornava mais leve. Alguns reclamavam que não gostavam, e eu respondia que tudo bem; que ali era um lugar para ele se conscientizar de procedimentos, se não quisesse usá-los depois era uma escolha. Mas o estudante precisava saber que era uma escolha, e que em alguns lugares a norma culta não pode ser abandonada. Precisava saber que o conhecimento da língua é um direito de todos, e transgredi-la podia ser uma escolha mais ou menos criativa.

Ensinar a norma culta de forma agradável sempre se faz um desafio!!! Se escrever era consciência de lingua- 
gem, a trajetória da disciplina deveria ser norteada por essa premissa. Outra premissa importante era a de que a linguagem visual tem uma força imensa na contemporaneidade e que a relação entre palavra e imagem pode dar-se de maneiras diversas. Acoplada a isso, a experiência com história oral lembrava-me do quanto o narrar era um gesto humano significativo. E de que grupos, instituições e movimentos sociais vinham descobrindo a importância e o valor de "contarem" a sua história. Thompson (1992), anteriormente citado, valoriza a oralidade como forma ativa e cidadã da construção da memória, apresentando-nos a ideia de que contar é compartilhar, e compartilhar é construir possibilidades de consolidar poderes individuais e coletivos de ação, reação e superação de situações de opressão, miséria, desrespeito ou submissão. Pela História Oral, revelam-se, amplificam-se e multiplicam-se as vozes dos sujeitos fazendo emergir as formas variadas do vivido na sociedade, em especial as de grupos subalternos. Assim, o uso da palavra vem se tornando uma possibilidade de construção de memória e ensinamentos de pessoas anônimas, com o compartilhamento de suas experiências de vida, suas potencialidades, sua cultura, e as positividades dos grupos populares. Além disso, reconhece-se o poder da palavra, da "história contada" e registrada, como possibilidade de denúncia das injustiças sociais, de registro da exploração, sofrimento, descumprimento dos direitos humanos. (MORAES; NUNES, 2016, p. 956)

O pesquisador ao utilizar-se da História Oral torna-se responsável por dar início, organizar, planejar, viabilizar a narrativa, desencadeando um dialogismo cujo desafio encontra-se em proporcionar o instante da fala de um sujeito, vivenciar a experiência da escuta e elaborar uma narrativa como resultante do processo de escuta. Ao se aceitar esse desafio importantes questões nortearão o trabalho do pesquisador: qual o significado desta experiência? Ou, para que serve a história falada? Para que serve a história da vida de um indivíduo comum? Qual sua importância?

Por surgir como um campo de ampliação das possibilidades das ciências sociais e, especificamente da história, que sempre utilizou, mesmo que de forma restrita, a oralidade, a História Oral, pela coleta de fontes orais, ampliou os limites de entendimento ou de recomposição do passado.

Na história política, na história social, na história cultural passou-se a produzir um conjunto de fontes orais e a partir 
delas realizar composições entre o escrito e o falado com intuito de verticalizar o conhecimento histórico em direção a aspectos cotidianos, ao tema da cultura, ao tema do imaginário e dos costumes." (MORAES; NUNES, 2016, p. 956 ).

Como pesquisadora do Diversitas - Núcleo de Estudos das Diversidades, Intolerâncias e Conflitos -, desloquei os procedimentos utilizados na construção do banco audiovisual de histórias de vida - que visa contribuir com a memória social, reconhecendo as narrativas de vida de toda e qualquer pessoa como um instrumento de memória e de ação - para a sala de aula, visando estimular a escrita de textos em que os alunos narrassem seu cotidiano, e para isso a escrita de crônicas veio como um instrumento, e recuperassem pela fotografia a narrativa de alguém da cidade de Cotia. Para isso, deveriam pedir que qualquer pessoa escolhesse uma fotografia e contasse onde ela se deu, que tempo era aquele, quem eram aquelas pessoas e ela mesma naquele contexto, como era a cidade naquele momento. A narrativa deveria ser gravada, com qualquer aparelho de celular, com imagem e voz ou só voz, transcrita e transcriada.

A atividade não se configurava, propriamente, como um exercício metodológico para a História Oral, já que era uma disciplina de Comunicação e Expressão. Com ela, pretendia trabalhar a diferença entre linguagem culta e popular, oralidade e escrita. Mas, pretendia, também, recuperar a ideia de narração para além dos gêneros literários. Desejava que os alunos compreendessem que a épica, na modernidade estética, dedica-se a histórias cotidianas, e que nós poderíamos fazer isso ouvindo as das pessoas que habitavam a cidade de Cotia.

A recuperação da ideia de narrar tem por matriz o ensino das tipologias textuais e da épica, porém, nela reverberava o belíssimo texto de Walter Benjamin (1987): O narrador. Nele, Benjamin conta-nos que o narrador apesar de familiar para nós, perdeu, de fato, seu sentido primeiro, e que "a arte de narrar está em vias de extinção” (BENJAMIN, 1987, p. 197).

$\mathrm{O}$ autor afirma serem raras as pessoas que narram devidamente, e o quão constrangedor se torna um encontro quando se pede, em um grupo, para alguém narrar alguma coisa. "É como se estivéssemos privados de uma faculdade que nos parecia segura e inalienável: a faculdade de intercambiar experiências." (BENJAMIN, 1987, p. 198)

Sua conclusão, ironicamente atualíssima, aponta como causa desse fenômeno as experiências em baixa. 
(...) e tudo indica que continuarão caindo até que seu valor desapareça de todo. Basta olharmos um jornal para percebermos que seu nível está mais baixo que nunca, e que da noite para o dia não somente a imagem do mundo exterior, mas também a do mundo ético sofreram transformações que antes não julgaríamos possíveis. (BENJAMIN, 1987, p. 198).

Para ele, a experiência vivenciada, e passada de pessoa a pessoa, sempre foi a fonte a que recorreram todos os narradores. E, entre as narrativas escritas, as melhores são as que menos se distinguiam das histórias orais transmitidas pelos inúmeros narradores anônimos.

Para mim, solicitar a escuta da vivência de um outro era remetê-la aos membros do discurso e à importância da reminiscência, pois, ainda tendo Benjamin por referência:

A reminiscência funda a cadeia da tradição. Que transmite o acontecimento de geração em geração. Ela corresponde à musa épica no sentido mais amplo. Ela inclui todas as variedades da forma épica. Entre elas, encontra-se em primeiro lugar a encarnada pelo narrador. Ela tece a rede que em última instância todas as histórias constituem entre si. Uma se articula na outra, como demonstraram todos os outros narradores, principalmente os orientais. (...) Quem escuta uma história está em companhia do narrador; mesmo quem a lê partilha dessa companhia. (BENJAMIN, 1987, p. 211).

Alguns trechos literários foram selecionados para que pudéssemos ver como aquelas vidas construídas pelas palavras traziam experiências que podiam coincidir com a vida das pessoas comuns habitantes das cidades ou do campo. Outra referência literária apoiava a escolha para se fazerem as pontes metafóricas entre as vozes dos personagens e a das pessoas comuns: A Literatura em Perigo, de Tzvetan Todorov (2009). Nesse livro, o crítico literário e historiador cultural discorre sobre a importância de ensinar a Literatura como um instrumento de compreensão da realidade, enfatizando o que ela tem a nos dizer sobre o mundo, uma determinada época e sobre nós mesmos.

Posteriormente, partiu-se para as vozes de Cotia. Após essa etapa e a transcrição das entrevistas, exercitamos, em sala de aula, com um trecho do trabalho de cada um dos alunos, a passagem da oralidade para a escrita, corrigindo os erros de língua portuguesa, tirando os vícios de linguagem, 
pontuando, reorganizando o discurso, sem que a coloquialidade se perdesse. Isso consistia no que José Carlos Sebe Mehy (2011) chama de transcriação. A transcriação propiciou uma consciência maior da estrutura semântica e sintática do discurso escrito, como também das diferenças que há entre oralidade e escrita.

Há que se considerar que o termo transcriação, cunhado por Haroldo de Campos para definir suas traduções (e emprestado por Mehy [2011]), no contexto da concepção poética haroldiana, pressupõe a interferência do tradutor, sem abandonar, porém, a essência original do signo estético. Ou seja, qualquer abandono deve expressar o desejo de fidelidade ao texto primeiro. O empréstimo de Mehy (2011) deve-se a sua concepção da escrita da história como uma escrita que se apropria de procedimentos romanescos, estabelecendo um diálogo constante com a Literatura, ainda que demarque bastante que Literatura é Literatura e História, História.

Mas ainda resta uma parte da pergunta a ser respondida. Por que fotografia no Curso de Comunicação e Expressão e por que escolhida pelos moradores da cidade de Cotia?

Nesse universo de selfies, facebook, instagram, a fotografia torna-se uma linguagem permissora para a reflexão sobre as narrativas que ali se condensam e os diálogos que se pode estabelecer com a língua e com a Literatura. Mário de Andrade, com o seu fotar, foi evocado para mostrar dois aspectos de suas fotografias: a de registro de um real e a de experimentação estética. Ambos coincidiam com a sua proposta - e dos modernistas como um todo - de expandir os limites da criação para outras linguagens, suportes, apropriando-se de procedimentos e conhecimentos provindos de outras áreas do saber e das artes.

A escolha não se devia apenas ao escritor modernista, mas também ao que representa a Fotografia.

Elas representam pequenos fragmentos que indicam os diferentes modos de vida dos atores sociais, a forma como compreendem o mundo, suas representações, o imaginário e as cenas muito próximas de seu cotidiano. As imagens parecem mais sedutoras do que a realidade, permitem ao observador fazer viagens por lugares nunca dantes imagináveis e descobrem o próprio mundo. (CANABARRO, 2005, p. 23).

Citando Le Goff, Canabarro (2005, p. 25) observa que a fotografia "revoluciona a memória", por multiplicá-la e 
democratizá-la, dando-lhe uma precisão e verdade permissora da conservação da memória do tempo e da evolução da sociedade. Pelas imagens fotográficas, veem-se os atores sociais colocados em cena, em diversas situações de atuação, o que permite o conhecimento dos cenários em que as atividades cotidianas desenvolvem-se. Mas, o que me parece mais importante dessa reflexão é o fato de que ela - a fotografia - serve de suporte para memória coletiva de um grupo, registrando cenas de um tempo continuum perenizadas no ato fotográfico, que se transportam para outras temporalidades, mesclando passado-presente. Pode-se destacar ainda a possibilidade dela como "uma alternativa a mais de leitura da realidade.” (CANABARRO, 2005, p. 26).

O autor recupera a reflexão de Maria Inez Turazzi, no texto Uma cultura fotográfica, da Revista do IPHAN, sobre o quanto

a fotografia foi e ainda é um recurso visual importante e eficaz para formação do sentimento de identidade, tanto individual quanto coletiva. Igualmente, é também um dos meios que materializa a 'visão de si, para si e para o outro' e uma visão do outro e de nossas diferenças. (CANABARRO, 2005, p. 37).

Estimular a construção de narrativas, por meio das fotografias, propiciava demonstrar que todas têm um valor significativo, apagado por uma indústria cultural impositora de modos estandardizados de vivências, e que havia mais heroísmo fora das telas da tv. Muitos chegavam dizendo que na sua casa ninguém tinha uma história importante ou interessante. Cabia-me responder que "ninguém morre tão pobre que não deixe alguma coisa atrás de si. Em todo caso, ele deixa reminiscência, embora nem sempre elas encontrem um herdeiro." (BENJAMIN, 1987, p. 212). Se nem sempre as reminiscências encontram herdeiro, convenci-os a serem os herdeiros da memória local.

As fotos sempre eram escolhidas por aqueles que seriam entrevistados, possibilitando a construção de narrativas com diferentes temáticas: lazer, imigração, cultura, natureza e até mesmo a guerra. Finalizada a transcriação, os entrevistadores deveriam escolher um trecho pequeno, que lhes parecia mais forte e exemplar do todo, para que se disponibilizasse ao público; as entrevistas, na íntegra, foram entregues visando a estruturação de um banco de histórias de vida de moradores da cidade de Cotia. Poucas das selecionadas 
encontram-se no blog, mas já conseguem dar uma dimensão do que pretende ser o projeto. Recupero duas delas, mesmo estando disponibilizadas on-line, para que se possa visualizar seu tom vital.

\section{1) Entrevistado: Antônio Batista}

Entrevistadores: Samara Rabello, Ed Carlos Mendes, Flavio Tauan, Helton Batista

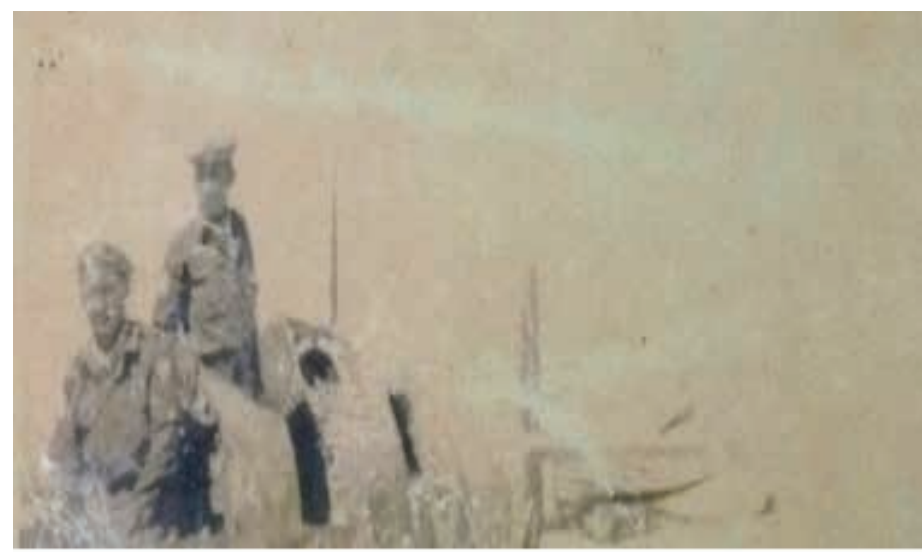

E nós brasileiros sofremos o que Deus duvida!

Hoje eu estou vivo; a caminho de oitenta e um anos, por graça de Deus!

Um dia, eu estava em um $\mathrm{PO}_{5}$ e se dirigiu na minha direção um pelotão: trinta e seis homens. Trinta e seis é um número de um pelotão, no mundo inteiro. Só tem menos quando alguém sofre uma baixa, o que significa que alguém morreu. Eu tinha um rádio Toc, me comuniquei com a minha retaguarda, a cem quilômetros de distância, e sabe o que me responderam, apesar de eu estar sozinho?

- Você tem bomba aí?

- Tenho.

- Está com uma metralhadora?

- Estou.

- Está com granada?

- Estou.

- Então se defenda.

O que eu ia fazer? Me defendi. Estou vivo... não sei o que aconteceu do outro lado... não gosto de falar sobre isso. (BATISTA, 2016).
Figura 1 - Fotografia de 1957. Fonte: Arquivo pessoal de Antônio Batista. 
A fala de Antônio Batista parecia vinda do texto de Walter Benjamin:

No final da guerra, observou-se que os combatentes voltavam mudos do campo de batalha não mais ricos, e sim mais pobres em experiência comunicável. E o que se difundiu dez anos depois, na enxurrada de livros sobre a guerra, nada tinha em comum com uma experiência transmitida de boca em boca. (BENJAMIN, 1987, p. 198).

A frase de Antônio - "não gosto de falar sobre isso" -, assim como o trecho do texto de Walter Benjamin, pode nos permitir ver o que representam as experiências de guerra e o narrar a vivência traumática. Esse senhor escolhe essa fotografia, compartilhando o que lhe ocorreu na Guerra do Egito, mas não consegue falar sobre isso. Em outros pontos de sua narrativa, lamenta que não há escuta para os brasileiros que lá estiveram.

A escuta implica em um reconhecimento! Como lembrou Benjamin, os livros - e eu acrescentaria agora filmes - nada têm em comum com essa experiência transmitida pela boca de um ex-combatente.

As frases ditas evocam em suas entrelinhas a bela imagem benjaminiana:

Uma geração que ainda fora à escola num bonde puxado por cavalos se encontrou ao ar livre numa paisagem em que nada permanecera inalterado, exceto as nuvens, e debaixo delas, num campo de forças de torrentes e explosões, o frágil e minúsculo corpo humano. (BENJAMIN, 1987, p. 198).

Talvez, pudéssemos reescrevê-la assim: um senhor que cresce numa região tão distanciada das areias do deserto Egípcio, que reside em um lugar em que o verde se faz bastante presente, se vê sob um céu - que não o protegerá -, e toma consciência do "frágil e minúsculo corpo humano".

2) Entrevistado: Francisco Pacífico de Medeiros Entrevistadores: Danilo Silva Santos; Nayara Medeiros

Nesta foto estão meus pais! Eram dois nordestinos, que saíram do Nordeste em 1952. Meu pai nasceu em 1894, e minha mãe, em 1904, na cidade de Florânia - Rio Grande do Norte. Sou mais um nordestino criado em São Paulo... Mas 
muitos nordestinos voltam pra sua terra natal e eu nunca voltei. Não conheço a cidade onde nasci; não tenho muita vontade de voltar.

\section{Mais ou menos!}

Não tem ninguém lá; não conheço ninguém lá; não sei se tenho parente ou não!

Nem sei o nome dos meus avós, como vou saber se tenho parente lá? Sai de lá com 4 anos de idade, vou conhecer o quê lá? Nada! Deve ter mudado tudo. Meus filhos são todos criados, todos educados, todos trabalhadores. É isso que importa na vida. Hoje tenho 10 netos e uma bisneta, não está bom?

...Ah! vou falar mais nada não! Vou deixar tudo, tudo na minha mente. (MEDEIROS, 2016).
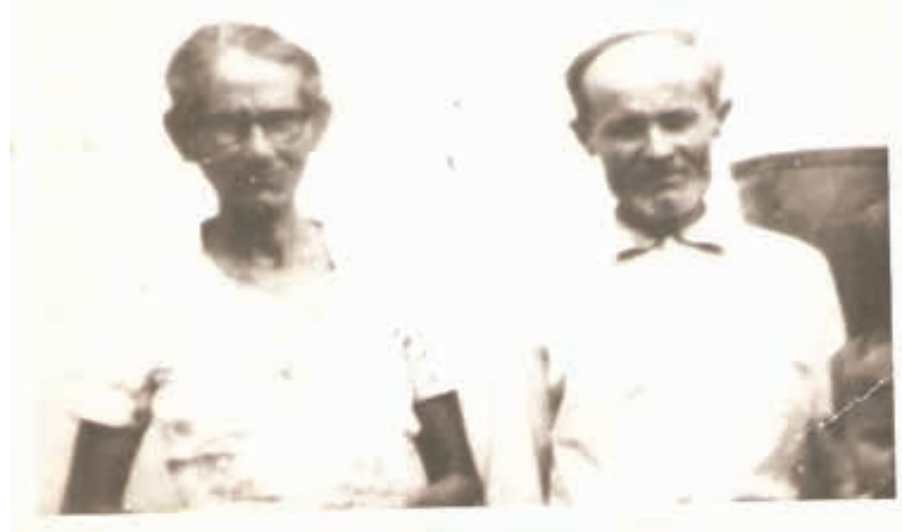

Francisco reaviva em seu discurso o verso de João Cabral de Melo Neto: "Somos muito Severinos, iguais em tudo na vida!". Reaviva também Vidas Secas, de Graciliano Ramos:

E andavam para o sul, metidos naquele sonho. Uma cidade grande, cheia de pessoas fortes. Os meninos em escolas, aprendendo coisas difíceis e necessárias. Eles dois velhinhos, acabando-se como uns cachorros, inúteis, acabando-se como Baleia. Que iriam fazer? Retardaram-se, temerosos. Chegariam a uma terra desconhecida e civilizada, ficariam presos nela. E o sertão continuaria a mandar gente para lá. O sertão mandaria para a cidade homens fortes, brutos, como Fabiano, Sinhá Vitória e os dois meninos.
Figura 2 - Pais de Francisco Medeiros.

Fonte: Arquivo pessoal de Francisco Medeiros. 
A terra-mãe deixa-lhe saudade, mesmo negando, pois suas frases se contrapõem: "Não conheço a cidade onde nasci; não tenho muita vontade de voltar. Mais ou menos!". E a identidade transparece ao afirmar: "Sou mais um nordestino criado em São Paulo...". Como os retirantes de Vidas Secas, ele prefere sonhar a falar: "Vou deixar tudo, tudo na minha mente." (MEDEIROS, 2016).

Com a proposta de recuperação das imagens e vozes de Cotia, História Fotografada, História (Com)Partilhada estendeu o papel da Universidade às questões sociais e concretas, fazendo-a funcionar como instituição que cumpre sua função social de formação de pessoas dignas, democráticas e livres, e, acima de tudo, de pessoas atentas a sua realidade e grupo sociais. Propunha-se, também, produzir e registrar memórias sociais, transformando essa memória em materiais e produtos culturais que extrapolassem os limites de uma disciplina e da sala de aula.

Com esse exercício, não só os moradores de Cotia, mas seus entrevistadores tornaram-se (re)construtores da memória local. Sherazades provocadoras do desejo de ouvir, ler e ver os personagens que - retomando uma vez mais Baudelaire permitem um retrato da Modernidade.

NOTAS

1. Em 2016, participei da Conferência Internacional de Cinema de Avanca, apresentando com Cláudia Moraes uma reflexão sobre as relações entre História e Etnografias Audiovisuais.

2. Disponível em <http://www.filmesdohomem.pt/>. Acesso em: 20 jan. 2017.

3. Disponível em <https://historiafotografada.wordpress.com/>. Acesso em: 25 jan. 2017.

4. Para a discussão sobre o ensino de Língua Portuguesa e a produção textual, os Parâmetros Curriculares, mesmo no ensino superior, fizeram-se um referencial bastante significativo para a concepção da disciplina de Comunicação e Expressão - para a elaboração da atividade com os alunos e para a fundamentação teórica acerca dos caminhos escolhidos.

5. Sigla do Exército para Posto de Observação. 


\section{Referências}

BATISTA, Antônio. Antônio Batista: entrevista [jun. 2016]. Entrevistadores: Samara Rabello, Ed Carlos Mendes, Flavio Tauan, Helton Batista. Entrevista concedida ao Projeto História Fotografada, História Compartilhada, em 02 de junho de 2016.

BAUDELAIRE, Charles. O Pintor da Vida Moderna. São Paulo: Autêntica Editora, 2010.

BENJAMIN, Walter. O narrador: considerações sobre a obra de Nikolai Leskov. In:___. Magia e Técnica, Arte e Política. São Paulo: Editora Brasiliense, 1987.

CANABARRO, Ivo. Fotografia, história e cultura fotográfica: aproximações. Revista Estudos Ibero-Americanos, PUCRS, v. 31, n. 2, p. 23-39, dez. 2005. Disponível em: <http://revistaseletronicas.pucrs.br/ojs/index.php/iberoamericana/ article/viewFile/1336/104>. Acesso em: 15 dez. 2017.

FLAUBERT, Gustave. Cartas Exemplares. Rio de Janeiro: Editora Imago, 1993.

MEDEIROS, Francisco Pacífico de. Francisco Pacífico de Medeiros: entrevista [out. 2016]. Entrevistadores: Danilo Silva Santos; Nayara Medeiros. Entrevista concedida ao Projeto História Fotografada, História Compartilhada, em 10 de outubro de 2016.

MEHY, José Carlos Sebe B. Guia Prático de História Oral. São Paulo: Editora Contexto, 2011.

MORAES, Claudia; NUNES, Sandra. Histórias Vividas, Histórias contadas: Produção Audiovisual de Histórias de Vida e Experiências de Cidadania na Cidade de São Paulo. Conferência Internacional de Avanca. Avanca: Edições Cine-Clube de Avanca, 2016. p. 956-963.

MORAES, Marcos. Mário e o Pirotécnico Aprendiz: Cartas de Mário de Andrade e Murilo Rubião. Belo Horizonte: Editora UFMG, 1995.

THOMPSON, Paul. A Voz do Passado: História Oral. São Paulo: Editora Paz e Terra, 1992.

TODOROV, Tzvetan. A Literatura em Perigo. São Paulo: Ed. Difel, 2009. 


\section{SANDRA REGINA CHAVES NUNES}

srcnunesı@gmail.com

Pós-Doutorado em Teoria Literária, pela Universidade Federal de Minas Gerais, e em História Social pela Universidade de São Paulo. Pesquisadora do Diversitas/USP e Professora do Programa de Pós-Graduação em Humanidades, Direitos e outras Legitimidades, do Diversitas/USP. Professora de Literatura, da Fundação Armando Álvares Penteado e de Comunicação e Expressão da Fatec. Vice-Coordenadora do Diversitas/Usp. Coordenadora do Grupo de Estudos Arte, Cultura e Subjetividade. Autora do Blog Reescrituras Rubianas, $<$ https://reescriturasrubianas.wordpress.com/>, e do ensaio biográfico sobre Murilo Rubião, em <www.murilorubiao.com.br>. Autora do blog História Fotografada, História (Com)Partilhada, <https:// historiafotografada.wordpress.com/>. 